\title{
Grading the severity of obstruction in patients with Chronic Obstructive Pulmonary Disease and morbid obesity
}

\author{
N. Barbarito1, E. De Mattia²
}

ABSTRACT: Grading the severity of obstruction in patients with Chronic Obstructive Pulmonary Disease and morbid obesity. N. Barbarito, E. De Mattia.

Aim. To evaluate the severity of airway obstruction in patients affected by chronic obstructive pulmonary disease (COPD) in the presence of concomitant restriction due to morbid obesity.

Methods. Lung function test, six-minute walking distance (6MWD) test, body mass index measurement (BMI), and determination of dyspnoea using the Modified Medical Research Council Dyspnoea Scale (MMRC) were performed on each patient referred to our department according to their individual respiratory diagnosis or symptoms. Analysis was performed on smokers or ex-smokers patients, with both dyspnoea and chronic productive cough, showing non fully reversible airflow obstruction, with normal-weight (NW: BMI 22 to $24 \mathrm{~kg} / \mathrm{m}^{2}$ ) or morbid-obesity (MO: BMI $\geq 40 \mathrm{~kg} / \mathrm{m}^{2}$ ).
Results. In 33 COPD patients, spirometric data differ between $\mathrm{NW}$ and MO only in fixed $\mathrm{FEV}_{1} / \mathrm{FVC}$ ratio $(50 \pm 9$ and $62 \pm 7$, respectively; $p=0.0001)$ and $\mathrm{FEV}_{1} / \mathrm{SVC}$ $\%$ of predicted $(57 \pm 15$ and $71 \pm 11$, respectively; $\mathrm{p}=$ 0.005). Furthermore, SVC was found to exceed FVC only in NW $(2.82 \pm 0.7 \mathrm{~L}$ and $2.08 \pm 0.9 \mathrm{~L}$, respectively; $p=$ 0.03). NW and MO differ significantly also in MMRC $(3.4 \pm 0.9$ vs $2.4 \pm 1$, respectively; $p=0.004)$, $6 \mathrm{MWD}$ in metres $(226 \pm 100$ and $331 \pm 110$, respectively, $p=0.007)$, 6MWD as \% predicted $(49 \pm 22$ and $81 \pm 23$, respectively; $\mathrm{p}=0.0003)$, and BODE index $(5.8 \pm 2$ and $3.6 \pm 2$, respectively; $p=0.003$ ).

Conclusions. There is a significant overgrading of obstruction in morbidly obese patients affected by COPD. Therefore, we suggest that an alternative grading system be used for patients with mixed ventilatory dysfunction. Monaldi Arch Chest Dis 2013; 79: 3-4, 121-127.

Keywords: Chronic Obstructive Pulmonary Disease (COPD), Morbid Obesity, Forced Expiratory Volume in the First Second $\left(\right.$ FEV $\left.V_{1}\right)$, Body Mass Index (BMI).

1 Emergency Department, Medicina 4, AO Salvini, Rho (Milan);

2 Pulmonary Rehabilitation, Centro Clinico NEMO, Fondazione Serena Onlus, Milan, Italy.

Correspondence: Nicola Barbarito, Pronto Soccorso, Medicina 4, AO Salvini, Corso Europa 250, 20017 Rho (MI), Italy; e-mail:nicola.barbarito@yahoo.it

\section{Introduction}

Chronic obstructive pulmonary disease (COPD) and obesity are major causes of morbidity and mortality worldwide and, according to current estimates, the global burden of these conditions is set to increase even further [1]. A potential link between obesity and COPD is also increasingly recognised [2], although very little is known about the mechanisms underlying this association. The risk of developing obesity is increased in patients with COPD as a result of a reduced level of physical activities in daily life in these patients compared with healthy agematched controls [3]. In addition, patients with COPD who receive repeated courses of systemic glucocorticosteroids could be at an increased risk of truncal obesity as a result of glucocorticoid mediated redistribution of stored energy and the stimulatory effect on intake [4].

While classification of obesity is based on one's body mass index (BMI), an index of weight to height ratio, as defined by the World Health Organization [5], spirometry is required for diagnosis and used for the graduation of COPD severity, according to the Global initiative for chronic Obstructive Lung Disease (GOLD) guidelines [6].

Obesity, which is defined as BMI of at least 30 $\mathrm{kg} / \mathrm{m}^{2}$, is considered as severe (or morbid) when BMI is $\geq 40 \mathrm{~kg} / \mathrm{m}^{2}$ [7]. It was found an inverse relationship between BMI and lung volumes assessed by spirometry $[8,9]$, with changes in lung function better demonstrated when BMI results greater than $45 \mathrm{~kg} / \mathrm{m}^{2}[10]$.

Current recommendations for COPD, which is defined as airflow obstruction that is not fully reversible, are that the severity of airflow obstruction should be based on the percentage predicted of the measured forced expiratory volume in the first second $\left(\mathrm{FEV}_{1} \%\right.$ pred) $[11,6]$.

To date no recommendations from the guidelines exist for the grading of obstruction in the presence of an additional restriction. Using forced expiratory volume in the first second $\left(\mathrm{FEV}_{1}\right)$ to gauge the degree of obstruction in mixed pulmonary disorders would be expected to overestimate the degree of obstruction as $\mathrm{FEV}_{1}$ is reduced from both the obstructive and the restrictive com- 
ponents of the underlying disease [12]. Obesity could cause a restrictive ventilatory defect, since lung volumes decrease as body mass index (BMI) increases $[8,9]$. To address the grading obstruction in the presence of concurrent pure extrapulmonary restrictive process, we embarked on a restrospective analysis of spirometries in patients affected by COPD of normal weight and morbid obesity.

\section{Materials and Methods}

Each patient referred to the Pulmonary Rehabilitation department at Villa Esperia Hospital (Salice T., Pavia, Italy) and depending on their respiratory diagnosis or symptoms, clinical history, spirometry, exercise capacity, dyspnoea and nutritional status were thoroughly assessed.

Smoking habits, respiratory history and symptoms were collected during an assisted interview.

Spirometry was performed by using a computerized pneumotachograph (MasterScreen Pneumo, Jager, Germany). The test procedures were performed by experienced and specially trained technicians, following the ATS recommendations [13], with each patient placed in a relaxed upright sitting position and provided with a nose-clip. Short acting and long acting bronchodilator medications were withheld six and twelve hours prior to testing, respectively. Vital capacity, defined as the difference between total lung capacity (TLC) and residual volume (RV), was measured as both a slow (slow vital capacity, SVC) and a forced (forced vital capacity, FVC) maximal expiration from TLC to RV. In patients showing airflow obstruction according to the current guidelines (i.e., $\mathrm{FEV}_{1} / \mathrm{FVC}$ less than $70 \%$ ), we assessed a reversibility test, performing on the same day a second spirometry approx. 15 minutes after the inhalation of four puffs of salbutamol, each containing $100 \mathrm{mcg}$ (total dose administered was $400 \mathrm{mcg}$ ), using a spacer mouthpiece. For analysis, we used only post-bronchodilator lung function values, in order to exclude from the study the patients showing fully reversible airflow obstruction (i.e., without any airflow obstruction after bronchodilator).

Exercise capacity was measured during a sixminute walking test, consistent with the ATS protocol [14]. The six-minute walk distance (6MWD) was measured considering the best out of two walk tests separated by $>60 \mathrm{~min}[14,15]$. The 6MWD was expressed in absolute values and as a percentage of predicted using published reference values [16].

Perception of dyspnoea was evaluated by the Modified Medical Research Council (MMRC) dyspnoea scale. The MMRC is a 0-4 point category scale which selects the best expression to define the dyspnoea levels among five expressions related to dyspnoea (grade 0 meaning breathlessness only with strenuous exercise, and grade 4 representing the most severe category, indicating that the patient is too breathless to leave the house or becomes breathless when dressing or undressing) [17].

Nutritional status was assessed by body mass index (BMI), that was computed as the ratio of body weight in kilograms to height in meters squared; height and weight were measured in a standing position without shoes, with patients wearing only light clothing [5].

In each patient included in the study, we also calculated the BODE index, a 11-point composite score (0 through 10) system that incorporates an assessment of airflow obstruction as $\mathrm{FEV}_{1} \%$ pred, 6MWD in metres, MMRC, and BMI: higher scores indicate poorer outcomes [18].

For inclusion in the study, patients had to satisfy all of the following criteria: over $45 \mathrm{yrs}$ of age, current or ex-smoker for $\geq 10$ pack-yrs, $\mathrm{FEV}_{1} / \mathrm{FVC}$ post-bronchodilator $<70 \%$, BMI $>21$ $\mathrm{kg} / \mathrm{m}^{2}$, with both dyspnoea and chronic productive cough, absence of diagnosis relating to any type of lung disease other than COPD. Patients were clinically stable for at least 6 weeks and were receiving optimal medical therapy according to the current guidelines. Exclusion criteria were: uncontrolled cardiovascular diseases, BMI 25 to 39.9 $\mathrm{kg} / \mathrm{m}^{2}$, and inability to perform the lung function and 6-min walk tests.

Our data were collected while both authors worked at Villa Esperia Hospital in Salice Terme (Pavia, Italy): the study period amounted to 28 months (January 12008 to April 30 2010).

All patients gave written informed consent to treatment of all data collected during their hospital stay.

Data are presented as mean \pm SD (unless otherwise stated), and were analysed by two-sample independent $t$ tests. Differences were regarded as significant with $\mathrm{p}$ values $<0.05$.

\section{Results}

Analysis was performed on a group of 33 subjects (age range $=48-87$ years, male $/$ female ratio $=$ $1 / 0.9$, BMI range $=21.1-61.6 \mathrm{~kg} / \mathrm{m}^{2}, \mathrm{FEV}_{1} \%$ pred range $=19-93 \%$ pred $)$, smokers or ex-smokers, both with dyspnoea and with chronic productive cough, showing $\mathrm{FEV}_{1} / \mathrm{FVC}$ ratio of $<70 \%$, with normal weight or morbid obesity.

Anthropometric and spirometric characteristics of the analysed patients are showed in table 1. Both absolute values and percent of predicted of $\mathrm{FEV}_{1}$ (figure 1), FVC and SVC did not differ significantly in the two groups. On the contrary, patients without obesity showed significantly lower mean values of both fixed $\mathrm{FEV}_{1} / \mathrm{FVC}$ ratios and $\mathrm{FEV}_{1} / \mathrm{SVC} \%$ of predicted. Furthermore, SVC was found to exceed FVC in patients with normalweight $(2.82 \pm 0.7 \mathrm{~L}$ and $2.08 \pm 0.9 \mathrm{~L}$, respectively; $\mathrm{p}$ $=0.03$ ), but not in patients with morbid-obesity $(2.61 \pm 0.9 \mathrm{~L}$ and $2.16 \pm 0.8 \mathrm{~L}$, respectively; $\mathrm{p}=0.15)$, as figure 2 shows.

Normal-weight COPD patients showed significantly higher dyspnoea (assessed with MMRC) than morbid-obese COPD patients: $3.4 \pm 0.9$ vs $2.4 \pm 1$, respectively ( $\mathrm{p}=0.004)$, as figure 3 shows.

Normal-weight COPD patients showed significantly lower exercise performance (assessed by 6MWD) than morbid-obese COPD patients, expressed both in absolute values $(226 \pm 100$ metres 
Table 1. - Demographic and lung function characteristics of the study patients

\begin{tabular}{|c|c|c|c|}
\hline & $\begin{array}{l}\text { Norm al-Weight } \\
\text { COPD patients }\end{array}$ & $\begin{array}{l}\text { Morbid-Ob ese } \\
\text { COPD patients }\end{array}$ & $p$ \\
\hline Sample size $(n)$ & 16 & 17 & \\
\hline Gender (Men:Women, $n$ ) & $10: 6$ & $7: 10$ & \\
\hline Age (years) * & $73 \pm 8$ & $69 \pm 7$ & 0.21 \\
\hline Weight $(\mathrm{kg}) *$ & $65 \pm 4$ & $126 \pm 26$ & $<0.0000001$ \\
\hline Height $(m) *$ & $1.67 \pm 5$ & $1.64 \pm 10$ & 0.36 \\
\hline $\mathrm{BMI}(\mathrm{kg} / \mathrm{m} 2) *$ & $23 \pm 1$ & $47 \pm 6$ & $<0.0000001$ \\
\hline $\mathrm{FEV}_{1}(\%$ pred $) *$ & $49 \pm 18$ & $57 \pm 18$ & 0.25 \\
\hline FVC (\%pred) * & $82 \pm 21$ & $73 \pm 19$ & 0.23 \\
\hline SVC (\%pred) * & $93 \pm 17$ & $81 \pm 20$ & 0.13 \\
\hline $\mathrm{FEV}_{1} / \mathrm{FVC}(\%) *$ & $50 \pm 9$ & $62 \pm 7$ & 0.0001 \\
\hline $\mathrm{FEV}_{1} / \mathrm{SVC}(\%$ pred $) *$ & $57 \pm 15$ & $71 \pm 11$ & 0.005 \\
\hline
\end{tabular}

* Data are presented as mean $\pm \mathrm{SD}$.

BMI: body mass index; $\mathrm{FEV}_{1}$ : forced expiratory in the first second; FVC: forced vital capacity; SVC: slow vital capacity.

vs $331 \pm 110$ metres, respectively $\mathrm{p}=0.007)$ and as $\%$ of predicted $(49.1 \pm 22 \%$ pred vs $81.5 \pm 23 \%$ pred, respectively $\mathrm{p}=0.0003$ ), as figures 4 shows.

The BODE index was found to be significantly lower (i.e., better) in morbid-obese than in normal-weight cases, as figure 5 shows: $3.6 \pm 2$ and $5.8 \pm 2$, respectively $(\mathrm{p}=0.003)$.

\section{Discussion}

Our study on patients with COPD shows that functional capacity, for the same grading of airflow obstruction, is better in the presence of a restrictive ventilatory defect due to morbid obesity.

\section{Overgrading airflow obstruction}

Using the $\mathrm{FEV}_{1} \%$ pred is recommended by means of the ATS/ERS guidelines to grade the severity of lung disease in the presence of obstruction and/or restriction [11] and by the GOLD guidelines to grade the severity of airflow obstruction in COPD patients without any recommendations in the presence of an additional restriction [6]. $\mathrm{FEV}_{1}$ is a strong and independent predictor of health status and has been found to be an independent predictor of both all-cause and respiratory mortality [19-21]. However, in the presence of mixed disorders, assessing the severity of the ob- structive component alone on the basis of $\mathrm{FEV}_{1}$ would be expected to over-estimate the degree of obstruction because the reduction in $\mathrm{FEV}_{1}$ would reflect the combined effects of both the obstructive and the restrictive components [12].

A restrictive ventilatory defect could be caused by obesity [8, 9]. In fact, an obese individual's accumulation of fat around the ribs, the diaphragm and the abdomen causes a decrease in chest wall compliance. The reduction in chest wall compliance is the primary reason for a decrease in expiratory reserve volume (ERV) and, consequently, in vital capacity (VC) observed in morbid obesity without any changes in residual volume (RV) due to lung parenchimal disease [22].

Normative predictive equations for spirometric measurements, plethysmographic lung volumes and TLCO are generally not corrected for weight. This could have implications for the clinical interpretation of pulmonary function tests in the obese [1].

We also found that normalweight and morbid-obese COPD patients did not differ in mean values of $\mathrm{FEV}_{1} \%$ pred, whereas patients without obesity showed lower mean values in both fixed $\mathrm{FEV}_{1} / \mathrm{FVC}$ ratios and $\mathrm{FEV}_{1} / \mathrm{SVC} \%$ of predicted.

In order to address the issue of grading obstruction in the presence of restriction, Balfe and colleagues [23] analyzed 147 patient pulmonary function tests with both restriction and obstruction,

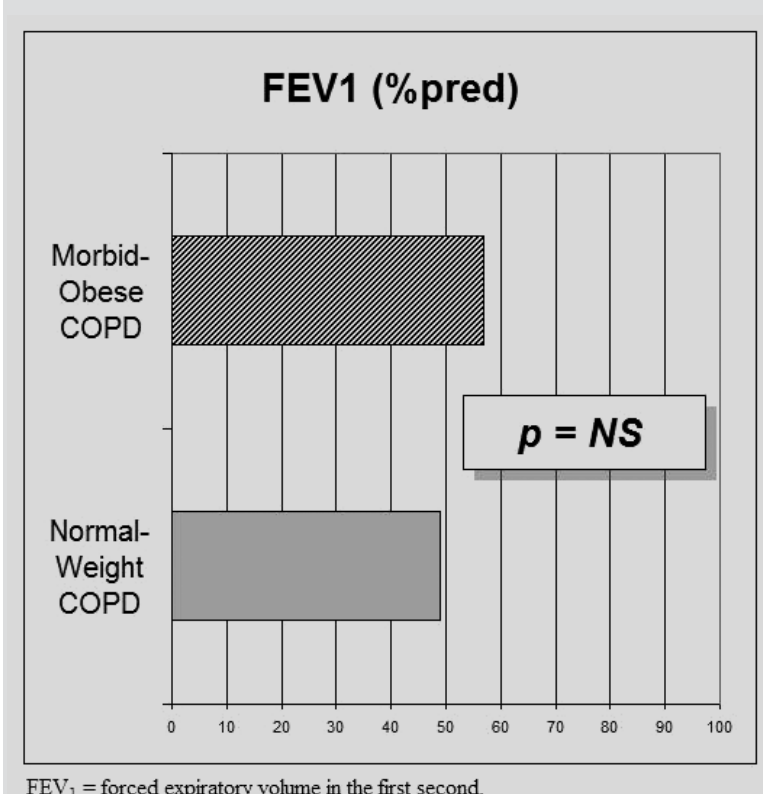

Data are presented as mean.

Fig. 1. - Gradation of COPD severity by spirometry. 


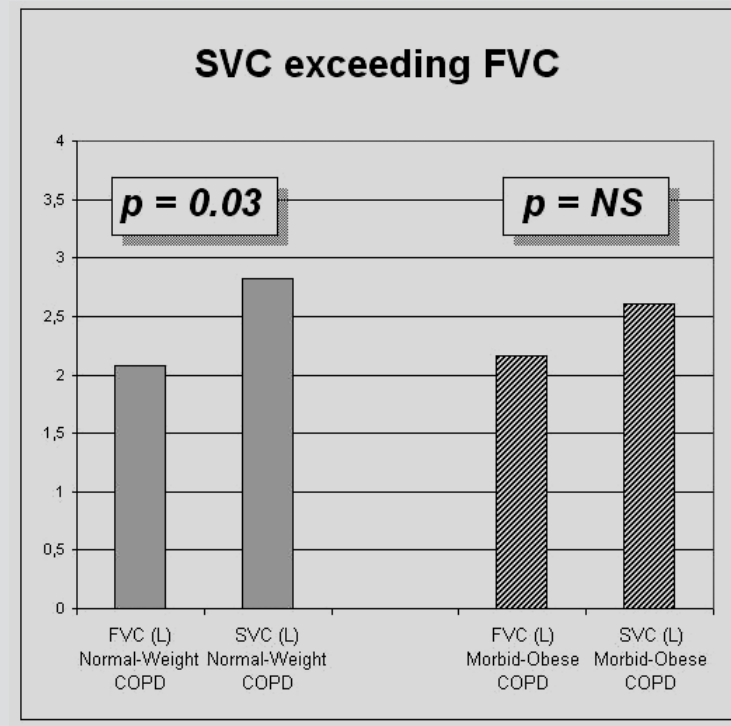

$\mathrm{FVC}=$ forced vital capacity. SVC $=$ slow vital capacity Data are presented as mean.

Fig. 2. - Vital capacity measured as both a slow and a forced maximal expiration from Total Lung Capacity to Residual Volume.

without specifying the subtended lung diseases. They determined the grading of airway obstruction by comparing the ATS recommendations (based on $\mathrm{FEV}_{1} \%$ pred) with the Intermountain Thoracic Society (ITS) recommendations (based on the $\mathrm{FEV}_{1} / \mathrm{FVC}$ ratio) [24]. The authors found that patients categorized as having severe or very severe obstruction were $90 \%$ using the ATS grading criteria (i.e., $\mathrm{FEV}_{1}<50 \%$ pred), and $3 \%$ using the ITS grading system (i.e., $\mathrm{FEV}_{1} / \mathrm{FVC}<4 \mathrm{CIs}$ ). In order to correct the complete reversal in the distribution of severity grades, which perhaps underestimated the true degree of obstruction, Balfe and colleagues recommended using the ITS grading in these patients but with modified CIs so as to normalize severity grade distribution: by using the proposed system, patients with mixed dysfunction resulted in $38 \%$ of cases as having severe obstruction (i.e., $\mathrm{FEV}_{1} / \mathrm{FVC}<2 \mathrm{CIs}$ ), therefore leading to a more balanced severity difference distribution [23].

More recently, Gardner and colleagues [25] studied 199 patients with mixed dysfunction, affected by a variety of obstructive, interstitial and extrapulmonary lung diseases. They found that adjusting the $\mathrm{FEV}_{1}$ for the degree of restriction results in a more appropriate distribution of the severity of obstruction: patients categorized as having severe or very severe obstruction amounted to $76 \%$ with the ATS grading (i.e., $\mathrm{FEV}_{1} \%$ pred), and $33 \%$ with the adjusted data (by dividing $\mathrm{FEV}_{1} \%$ pred by TLC $\%$ of predicted). In support of this, the authors demonstrate that the adjusted $\mathrm{FEV}_{1} \%$ pred correlates better than the unadjusted value with the RV/TLC ratio, another index of airflow obstruction, suggesting that the adjusted value more accurately reflects the degree of obstruction [25].

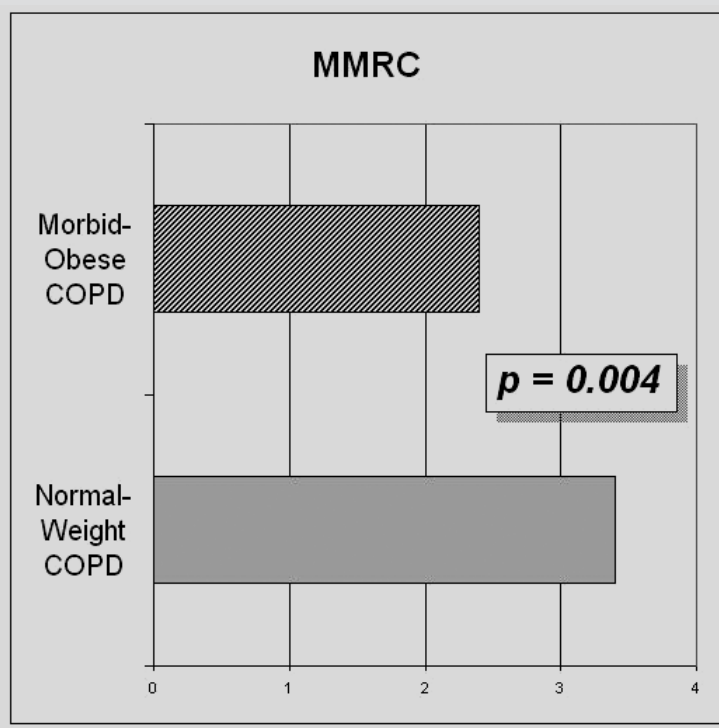

MMRC $=$ Modified Medical Reserch Council dyspnoea scale.

Data are presented as mean.

Fig. 3. - Dyspnoea.

Furthermore, we found that both SVC and FVC, as well as $\mathrm{FEV}_{1}$, did not differ between normalweight and morbid-obese COPD patients, both in terms of absolute values and as \% of predicted. However, SVC was found to exceed FVC in patients with normal-weight, but not in patients with morbid-obesity. We believe that this finding is consistent with a recent paper by O'Donnell and colleagues stated that, with increasing BMI, subjects with airway obstruction (greatly in patients with the most severe airway obstruction) had consistent reductions in lung hyperinflation [26]. Indeed, the pathological hallmark of COPD are inflammation of the small airways (bronchilolitis) and destruction of lung parenchyma (emphysema). Bronchiolitis narrows and obliterates the airways lumen and actively constricts the airways; emphysema reduces the elastic recoil of the lung and the elastic load applied to the small airways [27]. The functional consequence of both these abnormalities is the non-fully reversible airflow obstruction characteristic of COPD. In such patients with small-airway collapse, FVC can be lower than SVC. Vital capacity reflects parenchimal properties in normal individuals [28, 29], but also airway properties in obstructed patients $[30,29]$. It was hypothesized that an increase in airflow may increase viscous pressure losses within narrowed peripheral airways, thus causing the transmural pressure to be less and airway closure to occur at somewhat higher lung volumes: the greater the bronchoconstriction, the lower the vital capacity after forced expiration [31].

Inability in patients with both COPD and obesity: Dyspnoea and Walk distance

Both COPD and obesity are independently linked to dyspnoea on exertion and poor function- 


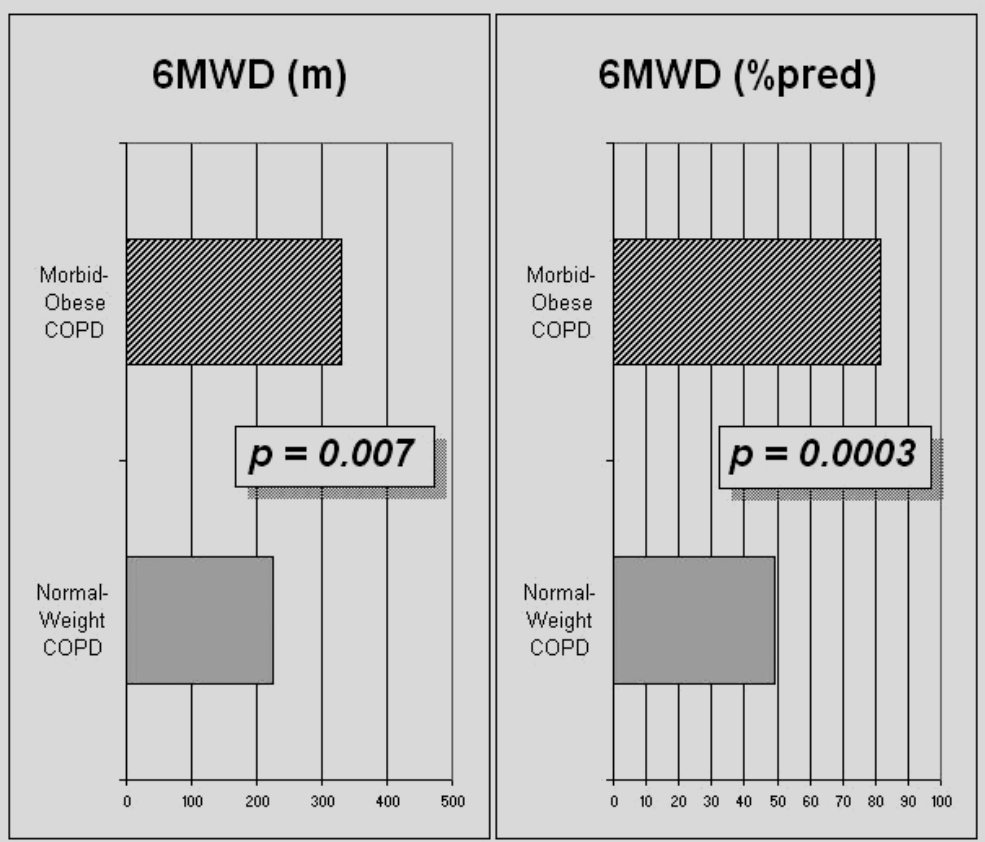

$6 \mathrm{MWD}=$ Six minutes walk distance.

Data are presented as mean. ty. Casanova and colleagues determined the 6MWD in 294 patients with COPD: its median value at baseline was $380 \mathrm{~m}$, and its annual rate of decline was $19 \%(16 \mathrm{~m} / \mathrm{yr})$ over 5 yrs [42]. Zutler and colleagues determined 6MWD in 369 adults without established COPD: the mean 6MWD was $522 \pm 90 \mathrm{~m}$, and in multiple linear regression analysis, adjusting for age and sex, the presence of obesity was associated with a $67 \pm 9 \mathrm{~m}$ decrement in 6MWD $(\mathrm{p}<0.001)$ [43].

In the present study, we found that normal-weight COPD patients showed higher dyspnoea (assessed with MMRC) and lower exercise performance (assessed by 6MWD) than morbid-obese COPD patients, for the same grading of airflow obstruction. Evidently, in normalweight patients the cause of breathlessness and functional exercise capacity are the abnormalities of dynamic ventilatory mechanics and ventilatory demand that characterise COPD, whereas in morbid obese patients there appeared to be

al capacity. The main symptoms of COPD are dyspnoea and limitation of physical activity, resulting in a complex integrated manner by several independent negative effects of dynamic hyperinflation (DH). Furthermore, DH leads to an increase in elastic and threshold loads on the inspiratory muscles (thus increasing the oxygen cost of breathing), maximal shortening the muscle fibers in the diaphragm and other inspiratory muscles (causing functional inspiratory muscle weakness), increasing the physiological dead space (leading to $\mathrm{CO}_{2}$ retention and arterial oxygen desaturation during exercise), and adversely affecting dynamic cardiac function [32]. On the other hand, obesity increases the work of breathing due to a reduction in chest wall compliance (attributed to the mechanical effects of fat on the chest wall) $[33,34]$ and a weakness of respiratory muscles (attributed to reduced chest wall compliance and/or lower operating lung volumes) [35, 34]. Furthermore, obese individuals have a higher metabolic demand at any given power output (as a result of the high oxygen cost of lifting heavy limbs) [36-38] and may have expiratory flow limitation at rest which, when compounded by high ventilatory requirements, leads to significant air trapping and dynamic increase in end-expiratory lung volume during exercise [36-38].

The 6-min walking distance (6MWD) test has gained importance in the assessment of functional exercise capacity in several kinds of diseases, including COPD [18, 39] and obesity [40, 41].

This test evaluates the global and integrated responses of the pulmonary, cardiovascular and muscular component and also reflects the functional exercise level for daily physical activities [14]. 6MWD was found to reduce both COPD and obesi- an overgrading of the respiratory disease.

In each of our patients, we also assessed their BODE index, a multidimensional grading system, which proved to be better than $\mathrm{FEV}_{1}$ in predicting the risk of hospitalization [44] and death [18] among patients with COPD. This multistage scoring system incorporates an assessment of symptoms (i.e., MMRC), nutritional state (i.e., BMI), and exercise capacity (i.e., 6MWD) together with spirometric measure of airflow (i.e., $\mathrm{FEV}_{1} \%$ pred) [18]. We excluded from our study the COPD pa-

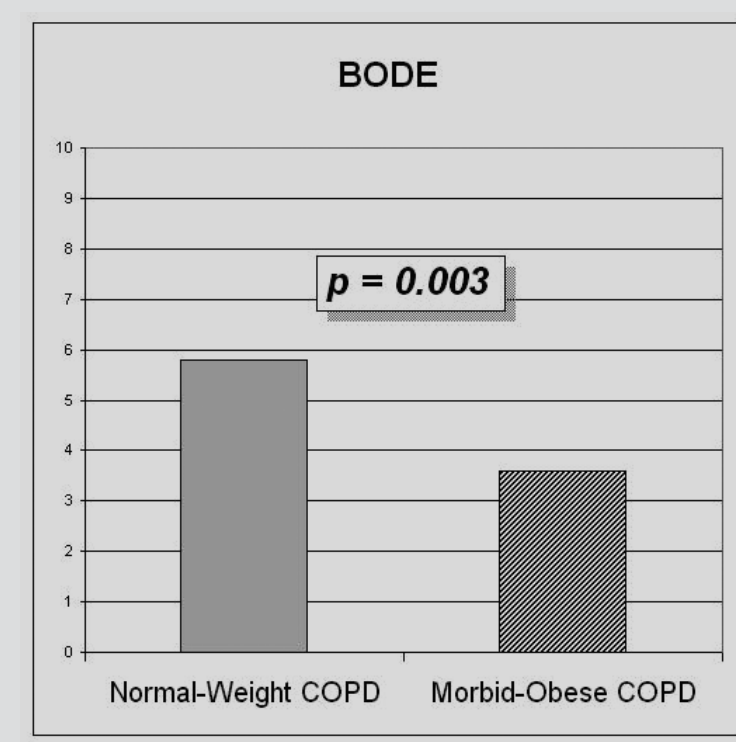

Data are presented as mean

Fig. 5. - Gradation of COPD severity by multistage scoring system. 
tients with $\mathrm{BMI} \leq 21 \mathrm{~kg} / \mathrm{m}^{2}$, as low BMI is associated with increased all-cause and COPD-related mortality unrelated to disease severity [45], and this inverse relation between BMI and survival is not linear but has an inflection point, which is just $21 \mathrm{~kg} / \mathrm{m}^{2}[18,45]$. Regarding BODE index (ranging from 0 to 10 points) the patient receives points ranging from 0 to 3 for all variables but BMI, for which the value is either 0 or 1 , because of the unique relation between BMI and survival described above [18]. Using such knowledge, we found that the BODE index was significantly lower (i.e., better) in the morbid-obese than in normalweight cases, in confirmation that dyspnoea and exercise limitation are lower in COPD patients with a likely overgraded airflow obstruction.

In conclusion, our results show that there is a significant overgrading of obstruction in morbid obese patients affected by COPD. Therefore, we suggest that an alternative grading system be used in patients with mixed ventilatory dysfunction such as obesity. We believe that any substantial downgrading of the severity of obstruction in morbid obese patients with COPD is clinically significant as such a change would inevitably lead to different treatment recommendations. Medications used to treat more severe obstructive lung diseases are expensive and can expose patients to unwanted or adverse side effects. If we are able to better diagnose the severity of obstruction, we could ultimately avoid using medications that are not suitable and incurring the costs and risks associated with their use [25].

\section{References}

1. Franssen FME, O'Donnell DE, Goossens GH, Blaak EE, Schols AMWJ. Obesity and the lung: 5. Obesity and COPD. Thorax 2008; 63: 1110-1117.

2. Poulain M, Doucet M, Major GC, et al. The effect of obesity on chronic respiratory diseases: pathophysiology and therapeutic strategies. CMAJ 2006; 174: 1293-9.

3. Pitta F, Troosters T, Spruit MA, Probst VS, Decramer M, Gosselink R. Characteristics of physical activities in daily life in chronic obstructive pulmonary disease. Am J Respir Crit Care Med 2005; 171: 972-7.

4. Dallman MF, la Fleur SE, Pecoraro NC, Gomez F, Houshyar H, Akana SF. Minireview: glucocorticoids-food intake, abdominal obesity, and wealthy nations in 2004. Endocrinology 2004; 145: 2633-8.

5. World Health Organization. Overweight and obesity: a new nutrition emergency? Monitoring the rapidly emerging public health problem of overweight and obesity: the WHO global database on body mass index. SCN News 2004: 5-12.

6. Vestbo J, Hurd SS, Agusti AG, et al. Global Initiative for Chronic Obstructive Lung Disease. Global strategy for the diagnosis, management and prevention of COPD. 2010. Available from: http://www.goldcopd.org/ uploads/users/files/GOLDReport_Aprile112011.pdf.

7. Yanovski SZ, Yanovski JA. Obesity. $N$ Engl J Med 2002; 346: 591-602.

8. Jones RL, Nzekwu MMU. The effects of body mass index on lung volumes. Chest 2006; 130: 827-833.

9. Cotes JE, Gilson JC, John C. Effects of inactivity and gain in weight upon lung function and indices of submaximal exercise. $J$ Physiol 1967; 188: 36P-38P.
10. D’Ávila Melo SM, De Melo VA, Meneze Filho RS, Santos FA. Effects of progressive increase in body weight on lung function in six groups of body mass index. Rev Assoc Med Bras 2011; 57: 499-505.

11. Pellegrino R, Viegi G, et al. Interpretative strategies for lung function tests. Eur Respir J 2005; 26: 948-968.

12. Culver BH. Obstructive? Restrictive? Or a ventilatory impairement? Chest 2011; 140: 568-569.

13. Standardization of Spirometry, 1994 Update. American Thoracic Society. Am J Respir Crit Care Med 1995; 152: $1107-1036$

14. ATS Committee on Proficiency Standards for Clinical Pulmonary Function Laboratories. ATS Statement: guidelines for the six-minute walk test. Am J Respir Crit Care Med 2002; 166: 111-117.

15. Sciurba FC, Slivka WA. Six-minute walktesting. Semin Respir Crit Care Med 1998; 9: 383-391.

16. Enright PL, Sherrill DL. Reference equations for the six-minute walk in healthy adults. Am J Respir Crit Care Med 1998; 158 (5 Pt 1): 1384-7.

17. Bestall J, Paul E, Garrod R, Garnham R, Jones PW, Wedzicha JA. Usefulness of the Medical Research Council (MRC) dyspnoea scale as a measure of disability in patients with chronic obstructive pulmonary disease. Thorax 1999; 54: 581-6.

18. Celli BR, Cote C, Marin JM, et al. The body-mass index, airflow obstruction, dyspnoea and exercise capacity index in chronic obstructive pulmonary disease. $N$ Engl J Med 2004; 350: 1005-1012.

19. Foxman B, Higgins ITT, Oh MS. The effects of occupation and smoking on respiratory disease mortality. Am Rev Respir Dis 1986; 134: 649-652.

20. Annesi I, Kauffmann F. Is respiratory mucus hypersecretion really an innocent disorder? Am Rev Respir Dis 1986; 134: 688-693.

21. Ortmeyer CE, Costello J, Morgan WKC, Swecker S, Peterson M. The mortality of Appalachian coal miners 1963 to 1971. Arch Environ Health 1974; 29: 67-72.

22. Salome CM, King GG and Berend N. Physiology of obesity and effects on lung function. $J$ Appl Physiol 108: 206-211, 2010.

23. Balfe DL, Lewis M, and Mohsenifar Z. Grading the Severity of Obstruction in the Presence of a Restrictive Ventilatory Defect. Chest 2002; 122: 1365-1369.

24. Morris AH, Kanner RE, Crapo RO, Gardner RM. Clinical pulmonary function testing: a manual of uniform laboratory procedures. Salt Lake City, UT: Intermountain Thoracic Society, 1984.

25. Gardner ZS, Ruppel GL, and Kaminsky DA. Grading the Severity of Obstruction in Mixed Obstructive-Restrictive Lung Disease. Chest 2011; 140: 598-603.

26. O'Donnell DE, Deesomchok A, Lam YM, et al. Effects of BMI on Static Lung Volumes in Patients With Airway Obstruction. Chest 2011; 140: 461-468.

27. Cosio Piqueras MG, Cosio MG. Disease of the airways in chronic obstructive pulmonary disease. Eur Respir J 2001; 18: Suppl 34, 41s-49s.

28. Anthonisen NR. Tests of mechanical function. In: Macklem PT, Mead J, eds. Handbook of Physiology. Section 3, Vol. III, Part 2. The Respiratory System: Mechanics of Breathing. Bethesda, MD, American Physiological Society, 1986; pp. 753-784.

29. Sutherland PW, Katsura T, Milic-Emili J. Previous volume history of the lung and regional distribution of gas. J Appl Physiol 1968; 25: 566-574.

30. Leith DE, Mead J. Mechanisms determining residual volume of the lungs in normal subjects. J Appl Physiol 1967; 23: 221-227.

31. Brusasco V, Pellegrino R, Rodarte JR. Vital capacities in acute and chronic airway obstruction: dependence on flow and volume histories. Eur Respir J 1997; 10: 1316-1320. 
32. O'Donnell DE, Banzett RB, Carrieri-Kohlman V, et al. Pathophysiology of dyspnoea in chronic obstructive pulmonary disease: a roundtable. Proc Am Thorac Soc 2007; 4: 145-68.

33. Chlif M, Keochkerian D, Mourlhon C, Choquet D, Ahmaidi S. Noninvasive assessment of the tension-time index of inspiratory muscles at rest in obese male subjects. Int J Obes (Lond) 2005; 29: 1478-83.

34. Sharp JT, Henry JP, Sweany SK, Meadows WR, Pietras RJ. The total work of breathing in normal and obese men. J Appl Physiol 1964; 43: 728-39.

35. Weiner P,Waizman J, Weiner M, Rabner M, Magadle $\mathrm{R}$, Zamir D. Influence of excessive weight after gastroplasty for morbid obesity on respiratory muscle performance. Thorax 1998; 53: 39-42.

36. Ofir D, Laveneziana P, Webb KA, O'Donnell DE. Ventilatory and perceptual responses to cycle exercise in obese women. J Appl Physiol 2007; 102: 2217-26.

37. Whipp BJ, Davis JA. The ventilatory stress of exercise in obesity. Am Rev Respir Dis 1984; 129: S90-2.

38. Babb TG, Buskirk ER, Hodgson JL. Exercise end-expiratory lung volumes in lean and moderately obese women. Int J Obes 1989; 13: 11-9.

39. Celli BR, MacNee W, ATS/ERS Task Force, Standards for the diagnosis and treatment of patients with COPD: a summary of the ATS/ERS position paper. Eur Respir $J$ 2004; 23: 932-946.

40. Imai K, Gregg EW, Chen YJ, Zhang P, de Rekeneire N, Williamson D. The association of BMI with functional status and self-rated health in US adults. Obesity (Silver Spring) 2008; 16: 402-08.

41. Jensen GL, Hsiao PY. Obesity in older adults: relationship to functional limitation. Curr Opin Clin Nutr Metab Care 2010; 13: 46-51.

42. Casanova C, Cote CG, Marin JM, et al. The 6-min walking distance: long-term follow up in patients with COPD. Eur Respir J 2007; 29: 535-540.

43. Zutler M, Singer JP, Omachi TA, Eisnerc M, Iribarren C, Katz P, Blanc PD. Relationship of obesity with respiratory symptoms and decreased functional capacity in adults without established COPD. Prim Care Respir J 2012; 21: 194-201.

44. Kian-Chung Ong KC, Earnest A, Lu SJ. A Multidimensional Grading System (BODE Index) as Predictor of Hospitalization for COPD. Chest 2005; 128: 38103816.

45. Landbo C, Prescott E, Lange P, Vwatbo J, Almdal TP. Prognostic value of nutritional status in chronic obstructive pulmonary disease. Am J Respir Crit Care Med 1999; 160: 1856-1861.

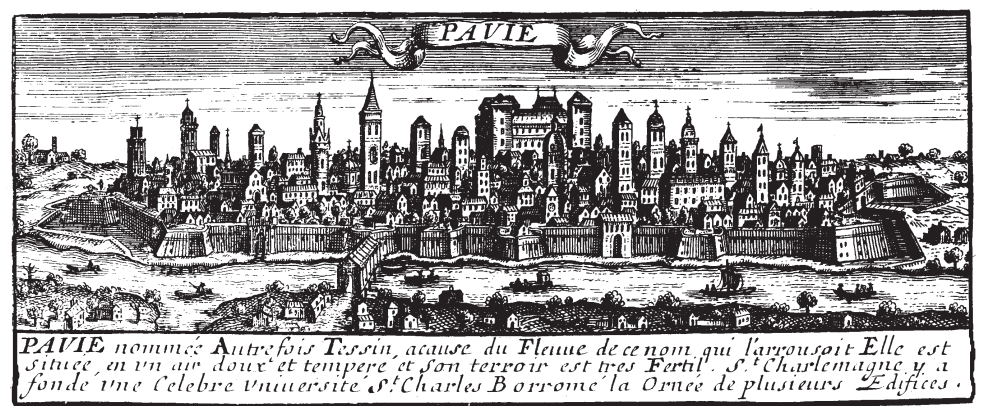

